\title{
Phenolic Plant Extracts Versus Penicillin G: In Vitro Susceptibility of Staphylococcus aureus Isolated from Bovine Mastitis
}

\author{
Fernanda Gomes ${ }^{1, *(\mathbb{D}}$, Maria Elisa Rodrigues ${ }^{1}\left(\mathbb{D}\right.$, Natália Martins ${ }^{2,3}{ }^{(0)}$, Isabel C.F.R. Ferreira ${ }^{4}$ \\ and Mariana Henriques ${ }^{1}$ (D) \\ 1 CEB, Centre of Biological Engineering, LIBRO-Laboratório de Investigação em Biofilmes Rosário Oliveira, \\ University of Minho, 4710-057 Braga, Portugal \\ 2 Faculty of Medicine, University of Porto, Alameda Prof. Hernani Monteiro, 4200-319 Porto, Portugal \\ 3 Institute for Research and Innovation in Health (i3S), University of Porto, Rua Alfredo Allen, \\ 4200-135 Porto, Portugal \\ 4 Centro de Investigação de Montanha (CIMO), Instituto Politécnico de Bragança, Campus de Santa Apolónia, \\ 5300-253 Bragança, Portugal \\ * Correspondence: fernandaisabel@deb.uminho.pt
}

Received: 29 July 2019; Accepted: 28 August 2019; Published: 31 August 2019

\begin{abstract}
Antibiotics are the elective drugs in bovine mastitis (BM) treatment, despite their low rates of efficiency and effectiveness and increasing risk of pathogen resistance. In this sense, it is urgent to discover new and effective antimicrobial agents to apply in BM control and even treatment. Plant extracts have been widely recognized as a rich source of phytochemicals with antimicrobial potential. Thus, the present work aims to compare the bioactivity of Eucalyptus globulus and Juglans regia extracts against Staphylococcus aureus bovine mastitis strains with penicillin G. At non-toxic concentrations, E. globulus exerted a bacteriostatic effect in planktonic cells and J. regia had no antimicrobial activity. Penicillin G, at minimum inhibitory concentration (MIC), demonstrated bactericidal activity, but just for S. aureus 3, 5, 6 and ATCC 25923, while the other strains seem to have acquired resistance. On the other hand, E. globulus and penicillin G in combination demonstrated synergy, being the most effective approach against $S$. aureus 1,2 and 4 . Thus, penicillin alone and in combination with E. globulus or J. regia seems to be promissory strategies to control bovine mastitis infections.
\end{abstract}

Keywords: bovine mastitis; Eucalyptus globulus Labill.; Juglans regia L.; penicillin G; Staphylococcus aureus

\section{Introduction}

Bovine mastitis (BM) is one of the most problematic infectious disorders with considerable economic losses for the dairy industry [1]. Antimicrobial agents, particularly antibiotics, have been widely used for the management and treatment of BM [2]. However, this kind of therapy has markedly promoted the emergence of antibiotic-resistant species, hampering mastitis management [1]. Staphylococcus aureus (S. aureus) is one of the most problematic causative agents of BM, being even recently highlighted by several studies that $S$. aureus contaminated milk from mastitis' infected animals can enter in the dairy production chain and be the origin of food contamination [3-5]. Therefore, the search for natural and effective antimicrobial drugs for preventive and therapeutic purposes of BM is an urgent need. Natural matrices are rich sources of a great variety of useful bioactive molecules for the development of new antimicrobial products [6]. As an example, Eucalyptus globulus Labill., rich in volatile compounds, is a well-known medicinal plant due to its biological and pharmacological 
properties [7-9]. E. globulus essential oil has a great application in folk medicine for the treatment of several diseases, including mastitis [10]. On the other hand, leaves of Juglans regia L. are also widely used as antimicrobial in complementary and alternative therapies [11,12].

Nowadays, several research groups are testing fractions and even extracts from J. regia in animal models with different pathologies aiming to find potential therapeutic benefits [11]. Adnan et al. (2018) suggested that the antimicrobial activity of plants is primarily due to the presence of phenolic compounds [13], and therefore the higher the extraction of phenolic compounds the greater the antimicrobial efficacy. Moreover, although alcoholic solvents such as methanol and ethanol are preferentially used in plant extractions it was shown that phenolic extraction is significantly improved when a small portion of water is added to organic solvents [14].

Considering their promisor antimicrobial properties [15] and aiming to overcome the problem of antibiotic resistance, in this work the antibacterial activity of Eucalyptus globulus and Juglans regia methanol-water extracts were compared with penicillin $\mathrm{G}$, alone and in combination, against $S$. aureus isolated from cows suffering mastitis. The evaluation of the cytotoxic potential of E. globulus and J. regia extracts were also performed.

\section{Results}

Table 1 shows the minimum inhibitory concentration (MIC) values for penicillin G. From the total BM isolates, three of them (i.e., S. aureus 1, 2 and 4 strains) presented an MIC value of $24 \mu \mathrm{g} / \mathrm{mL}$, while the remaining ones, including S. aureus reference strain ATCC 25923, presented an MIC value of $0.4 \mu \mathrm{g} / \mathrm{mL}$ (Table 1 ).

Table 1. Minimum inhibitory concentration (MIC) of penicillin G against S. aureus isolates $(n=7)$, determined by the broth microdilution method.

\begin{tabular}{cccccccc}
\hline \multicolumn{7}{c}{ MIC $(\mu \mathrm{g} / \mathrm{mL})$} \\
\hline \multirow{2}{*}{ Strains } & S. aureus & S. aureus & S. aureus & S. aureus & S. aureus & S. aureus & S. aureus ATCC \\
& 1 & 2 & 3 & 4 & 5 & 6 & 25923 \\
\hline Pen G & 24 & 24 & 0.4 & 24 & 0.4 & 0.4 & 0.4 \\
\hline \multicolumn{8}{c}{ Pen G: Penicillin G. }
\end{tabular}

The MIC values obtained for penicillin G demonstrated that $S$. aureus 1, 2 and 4 strains present a similar level of susceptibility, while S. aureus 3, 5, 6 and S. aureus ATCC 25923 may be included in another group of susceptible strains. Therefore, based on their resistance patterns it was possible to divide the tested strains into two distinct groups, i.e., most resistant (S. aureus 1, 2 and 4) and less resistant (S. aureus ATCC 25923, 3, 5 and 6).

In order to know which concentrations of plant extracts to use in this study, the cytotoxicity of E. globulus and J. regia was evaluated. The percentage of viable animal cells obtained after exposure to both plant extracts was closely related to those of the negative control (cells grown without plant extracts), at concentrations $\leq 100 \mu \mathrm{g} / \mathrm{mL}$ of E. globulus (Figure 1a) and $\leq 195 \mu \mathrm{g} / \mathrm{mL}$ of J. regia (Figure $1 \mathrm{~b}$ ) extracts $(p>0.05)$. Specifically, for the E. globulus extract, at a concentration of $195 \mu \mathrm{g} / \mathrm{mL}$, the percentage of viable cells (63.9\%) was close to the limit to be considered non-cytotoxic $(70 \%)$ based on ISO 10993-5:2006. Considering the results obtained, the antibacterial activity of E. globulus and J. regia (at non-cytotoxic concentrations) and penicillin G (at MIC) was tested alone and in combination against planktonic cells of $S$. aureus. Moreover, based on the MIC pattern of results, only a representative strain from each group was selected to be presented in Figure 2, namely S. aureus 1 and S. aureus ATCC 25923. 


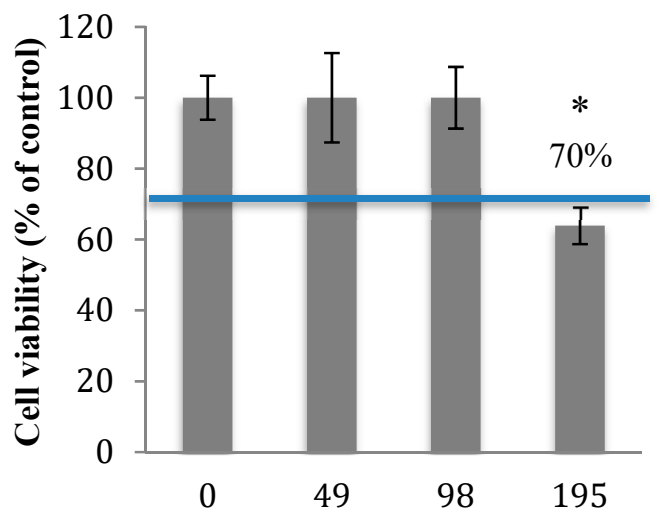

E. globulus concentration $(\mu \mathrm{g} / \mathrm{mL})$

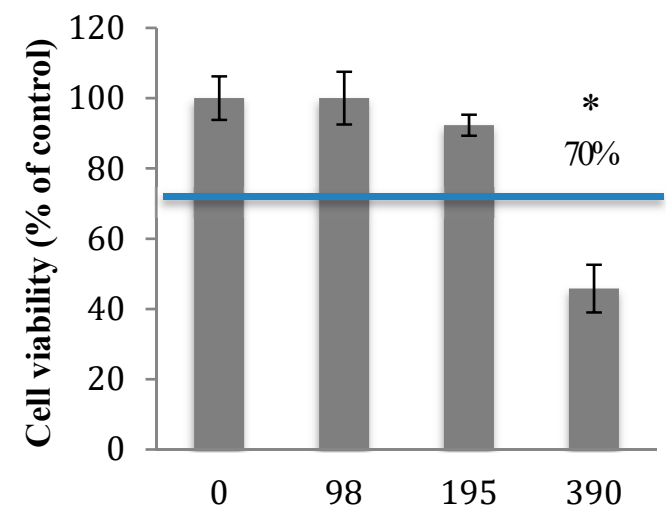

J. regia concentration $(\mu \mathrm{g} / \mathrm{mL})$

(b)

Figure 1. Fibroblast $3 \mathrm{~T} 3$ viability after $24 \mathrm{~h}$ of contact with different concentrations of E. globulus (a) and J. regia (b) extracts, measured with MTS assay. The negative control allowed the perfect growth of the cells (cells grown without extracts; $100 \%$ viability). ${ }^{*} p<0.05$.

The use of E. globulus alone seems to exert a bacteriostatic effect against S. aureus until $8 \mathrm{~h}$ of incubation (Figure 2). Over time, E. globulus and J. regia alone presented a slight inhibitory effect, when compared with the positive control (Figure 2). Regarding penicillin G, no bioactivity was observed against $S$. aureus 1,2 and 4 (Figure 2a), with only bactericidal effects being evident against all the other strains selected (Figure $2 b$ ). In this case, penicillin $G$ promoted a log reduction ranging from 2.78 to 5.76 , after $24 \mathrm{~h}(p<0.05)$. On the other hand, when both extracts were combined with penicillin $\mathrm{G}$, the most effective antimicrobial activity was observed for $S$. aureus 1, 2 and 4 strains, compared to the antimicrobial agent tested alone (Figure 2a).

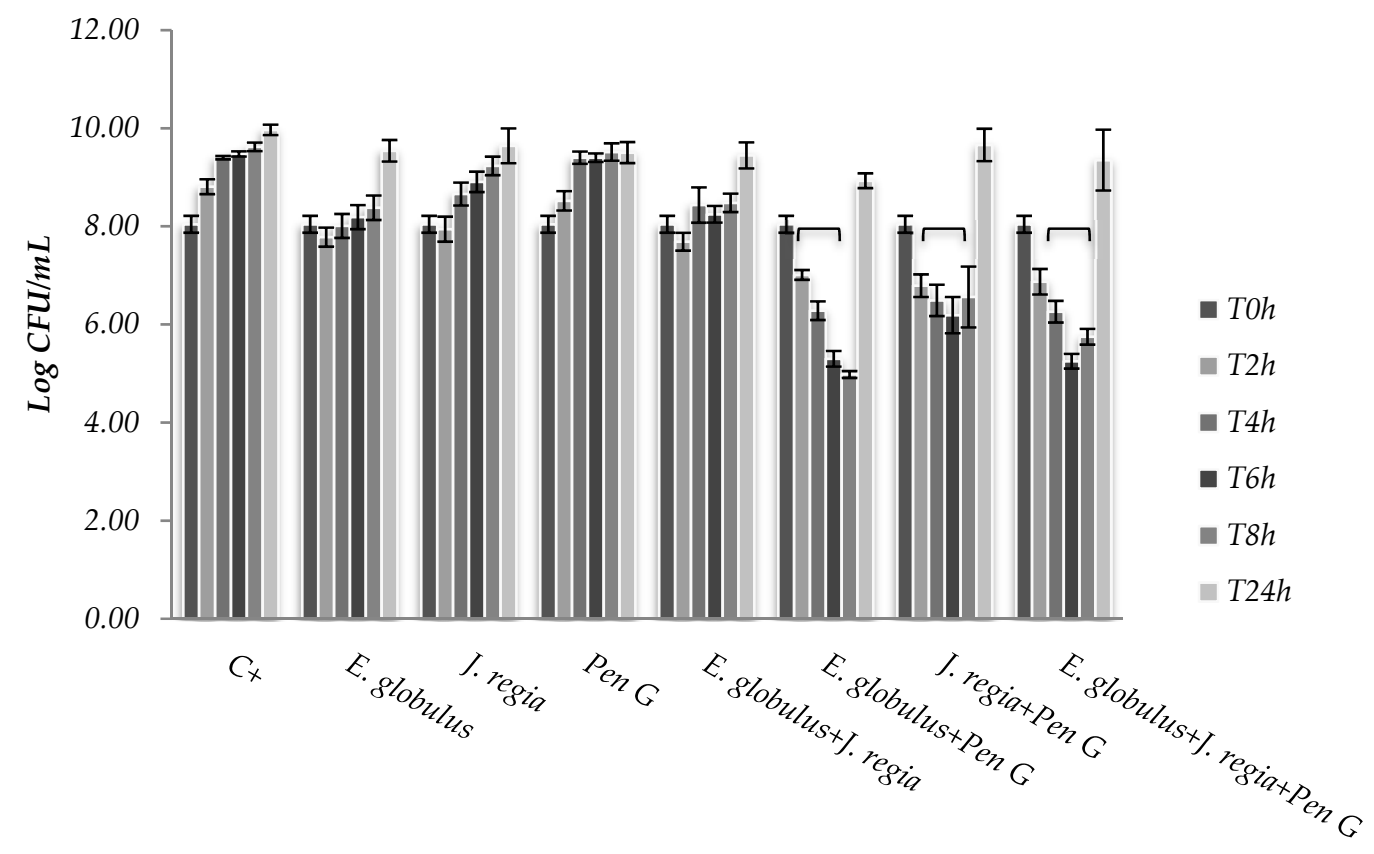

(a)

Figure 2. Cont. 


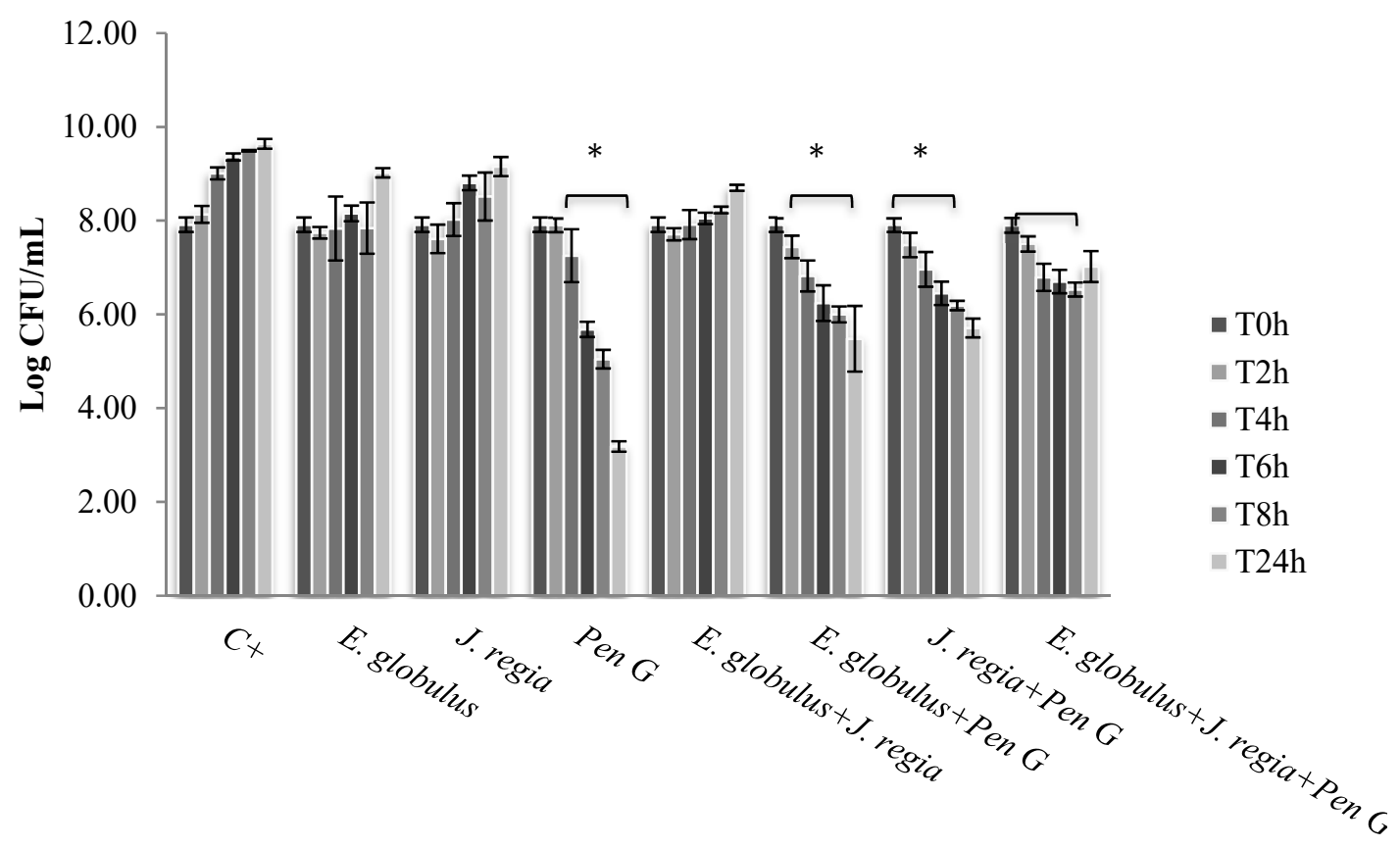

(b)

Figure 2. Colony forming units (CFUs) of Staphylococcus aureus 1 (a) and ATCC 25923 (b), cultured within methanol-water extract of E. globulus $(100 \mu \mathrm{g} / \mathrm{mL})$, J. regia $(195 \mu \mathrm{g} / \mathrm{mL})$ and penicillin G (MIC), alone and in combination. $\mathrm{C}+-$ Positive control. ${ }^{*} p<0.05$.

\section{Discussion}

Penicillin is the most commonly used drug in the treatment of BM, even though their use is closely related to the increasing appearance of resistant strains [16]. In this sense, the assessment of the feasibility of using a combinatory strategy might provide considerable benefits, even allowing a greater efficacy (synergistic or potentiation reaction) at lower doses, reducing the development of drug-resistant species and even preventing the occurrence of side effects [17]. Thus, the evaluation of the antimicrobial activity of both plant extracts against planktonic cells of $S$. aureus BM isolates and S. aureus ATCC 25923 were performed under different conditions, which included: The use of E. globulus and J. regia alone and in combination, at non-cytotoxic concentrations; and the use of penicillin G at MIC value, alone and in combination with both plant extracts.

Then, the assessment of the cytotoxic potential and safety of both extracts was performed, and the results obtained for both matrices revealed that E. globulus and J. regia are non-toxic to animal cells at concentrations $\leq 100$ and $\leq 195 \mu \mathrm{g} / \mathrm{mL}$, respectively (Figure $1 \mathrm{a}, \mathrm{b}$ ). When both extracts were used at non-cytotoxic concentrations and compared with the antibacterial effect exerted by penicillin $\mathrm{G}$, the most prominent effect was observed to E. globulus extract against $S$. aureus 1, 2 and 4 strains (Figure 2a). For those strains, E. globulus evidenced a bacteriostatic effect until 8 hours of incubation. On the other hand, no antimicrobial effects were observed with penicillin G. In fact, although E. globulus exerted a similar bacteriostatic effect against the remaining strains, penicillin $G$ was the most effective agent, even exerting bactericidal effects (Figure 2b). Moreover, the obtained penicillin G MIC value to S. aureus 1, 2 and 4 strains was nearly 60 times higher than those obtained with S. aureus 3, 5, 6 and ATCC 25923 (Table 1), being, therefore, more resistant to penicillin G.

Synergistic effects were observed to $S$. aureus 1, 2 and 4 strains to the combinations E. globulus + penicillin $G$ and J. regia + penicillin G being first the most effective combination. However, the combination of these agents with J. regia did not further improve their antimicrobial activity. 
For these strains, plant extracts combined with penicillin $\mathrm{G}$ seemed to exert an immediate antimicrobial effect and the number of colony forming units (CFUs) decreased dramatically up to $8 \mathrm{~h}$. However, CFUs increased after $24 \mathrm{~h}$ incubation under the combination strategy (Figure 2a). Perhaps a new dose of plant extracts will necessarily be added after $6 / 8 \mathrm{~h}$ of treatment in order to obtain a higher and prolonged inhibitory activity. Concerning the S. aureus ATCC 25923, 3, 5 and 6 strains, penicillin G used alone still continued to be more effective than all the combinations tested. Moreover, penicillin $G$ in combination with plant extracts promoted, over time and up to $24 \mathrm{~h}$ of incubation, an increasing CFU log reduction probably due to the bactericidal effect of penicillin $\mathrm{G}$ (Figure 2b).

In general, this study revealed an interesting synergy of E. globulus or J. regia in combination with penicillin $G$ for most penicillin-resistant strains. Penicillin $G$ is a $\beta$-lactam antibiotic that inhibits cell wall synthesis. On the other side, the major phenolic compounds found in E. globulus extract belong to the phenolic acids (gallic acid, caffeic acid and ellagic acid) and the flavonoids (quercetin) group [15]. Specifically, the most common phenolic compounds found in E. globulus and J. regia extracts are caffeic acid derivatives and quercetin. When looking at the specific mechanisms of action, gallic and caffeic acids mainly inhibit the $\mathrm{H}^{+}$-ATPase, responsible for ATP production [18] The ellagic acid interacts with enzymes, consequently inhibiting their interaction with proteins [18]. Flavonoids affect the cell wall stability, promoting the disruption of cell structure [18]. Thus, the major phenolic compounds found in E. globulus and J. regia, gallic acid and quercetin derivatives, respectively, demonstrated a great ability to strengthen the bioactivity of $\beta$-lactam antibiotics by inhibiting the penicillin binding protein $2 \mathrm{a}$ (PBP2a) [19]. This peptidoglycan transpeptidase, in cooperation with the transglucosylase domain of PBP2 of S. aureus, is responsible for bacterial proliferation when exposed to $\beta$-lactam antibiotics [20]. Therefore, PBP2a inhibitors are usually used to overcome the antibiotics resistance and it is probably the mechanism responsible for the synergy observed when antimicrobials combination was tested.

It is also interesting to highlight that, to the most susceptible strains, penicillin $G$ is still the most effective approach. Moreover, it should be also pointed out that, in vitro studies might not reflect what really occurs in vivo. In fact, during administration, natural molecules suffer numerous biochemical reactions in organisms while some others need to be metabolized to become biologically active, and other become inactive [21]. Furthermore, the in vivo bioavailability of antimicrobial drugs may vary both due to endogenous factors and even inter and intra-individual variations.

\section{Materials and Methods}

\subsection{Samples}

In this study, the leaves of two plant species were used: Eucalyptus globulus Labill. (blue gum) from commercial origin (Cantinho das Aromáticas, an organic and certified farm from Vila Nova de Gaia, Portugal), and Juglans regia L. (walnut) harvested in Trás-os-Montes, Bragança, Portugal, collected and identified according to Santos et al. [12].

\subsection{Standards and Reagents}

Methanol was of analytical grade purity and supplied by Pronalab (Lisbon, Portugal). Tryptic Soy Broth (TSB) medium and Tryptic Soy Agar (TSA) were purchased from Liofilchem (Roseto degli Abruzzi, Italy) and Merck (Darmstadt, Germany), respectively, and prepared according to the manufacturer's instructions. Water was treated in a Milli-Q water purification system (TGI Pure Water Systems, Greenville, SC, USA). Penicillin G was purchased from Sigma Chemical Co., (St. Louis, MO, USA).

\subsection{Preparation of the Extracts}

Methanol-water extracts were obtained by extracting each plant sample $(1 \mathrm{~g})$ with $30 \mathrm{~mL}$ of methanol-water $(80: 20, v / v)$ at $25^{\circ} \mathrm{C}$ and $150 \mathrm{rpm}$ for $1 \mathrm{~h}$, and filtering through Whatman No. 4 paper. The final residue was then extracted with an additional $30 \mathrm{~mL}$ portion of methanol-water mixture. Each one of the combined extracts was evaporated at $35^{\circ} \mathrm{C}$ under reduced pressure (rotary evaporator 
Büchi R-210, Flawil, Switzerland) and then lyophilized (FreeZone 4.5, Labconco, Kansas City, MO, USA). The lyophilized methanol-water extracts were re-dissolved in water to obtain stock solutions at $50 \times 10^{3} \mu \mathrm{g} / \mathrm{mL}$, from which several dilutions were prepared. E. globulus extract was previously characterized in terms of chemical compounds [12,15,22], and J. regia (methanolic and aqueous extracts) was previously characterized by Santos et al. [12].

\subsection{Determination of Minimal Inhibitory Concentrations (MICs)}

Seven S. aureus were selected for this work: Reference strain (S. aureus ATCC 25923) and six BM isolates, kindly provided by the Portuguese lab (Segalab-Laboratório de Sanidade Animal e Segurança Alimentar SA). Minimal inhibitory concentration (MIC) of penicillin G was determined by the microbroth dilution technique. The determination of MIC values was performed by the serial two-fold dilutions method at concentrations ranging from $2 \times 10^{-2} \mu \mathrm{g} / \mathrm{mL}$ to $24 \mu \mathrm{g} / \mathrm{mL}$. The final cell concentration used was $5 \times 10^{5}$ cells $/ \mathrm{mL}$. Then, 96 -well plates (Orange Scientific, Braine-l'Alleud, Belgium) were incubated at $37^{\circ} \mathrm{C}$ for $24 \mathrm{~h}$. Samples (cells grown with penicillin G) and bacteria-free controls (positive controls) were also included. After visualization of the resultant plate, MIC values were correspondent to the antibiotic concentration where there was no visible growth, or even bacteriostatic effect by comparison with the positive controls. The number of viable cells was assessed through determination of a number of colonies forming units (CFUs), after $24 \mathrm{~h}$ of incubation at $37^{\circ} \mathrm{C}$. The results were presented as total of CFUs (Log CFUs). All the experiments were carried out in triplicate and repeated at three different moments.

\subsection{Cytotoxicity Assay}

The effect of E. globulus and J. regia on cell viability was assessed by the MTS ((3-[4,5carboxymethoxyphenyl]-2-(4-sulfophenyl)-2H-tetrazolium), Promega) assay, using human primary fibroblast cell lines (3T3-CCL 163-from the American Type Culture Collection). Briefly, the cells were trypsinized and seeded in 96-well plates at a final concentration of $1 \times 10^{5}$ cells $/ \mathrm{mL}$, in Dulbecco Modified Eagle Medium (DMEM, Biochrom $\mathrm{GmbH}$ ) supplemented with $10 \%$ of fetal bovine serum (FBS, Sigma Aldrich) and $1 \%$ of penicillin/streptomycin (Biochrom AG), at $37{ }^{\circ} \mathrm{C}$ and $5 \% \mathrm{CO}_{2}$. After $24 \mathrm{~h}$ of incubation, the cell cultures were treated with several concentrations of E. globulus and J. regia dissolved in DMEM complete medium, for a further $24 \mathrm{~h}$. After this time, the wells were washed twice with phosphate buffered saline (PBS) (1X), and then $150 \mu \mathrm{L}$ of MTS with DMEM without phenol (1/10, $v / v)$ (Sigma Aldrich) were added to each well. After $1 \mathrm{~h}$, the cell viability was assessed by reading the absorbance at $490 \mathrm{~nm}$ (absorbance of the orange formazan product) in a microplate reader Sunrise (Männdorf, Switzerland). The results were expressed as a \% of viable cells, corresponding the $\mathrm{OD}_{490}$ to cells grown without extracts as $100 \%$ of cell viability. Dimethyl sulfoxide (DMSO, Sigma Aldrich) at $50 \%(v / v)$ in DMEM was used as positive control.

\subsection{S. aureus Susceptibility to Eucalyptus globulus, Juglans regia and Penicillin G}

The antibacterial activity of E. globulus $(100 \mu \mathrm{g} / \mathrm{mL})$ and J. regia $(195 \mu \mathrm{g} / \mathrm{mL})$ in planktonic cells was tested against seven different $S$. aureus strains: One reference strain (S. aureus ATCC 25923) and six clinical isolates (S. aureus 1, 2, 3, 4, 5 and 6). For that, strains $\left(1 \times 10^{6}\right.$ cells/mL) were grown in Erlenmeyer flasks in the presence of each selected plant extract, alone and in combination. Then, the cells were incubated at $37^{\circ} \mathrm{C}$ and $120 \mathrm{rpm}$ for $24 \mathrm{~h}$. The surviving viable bacteria were obtained by CFU assay after $0,2,4,6,8$ and $24 \mathrm{~h}$ of incubation. The antimicrobial activity of selected plant extracts was compared with the effect of penicillin $\mathrm{G}$ at determined MIC concentration, following the same procedure. Antibacterial activity of penicillin $\mathrm{G}$ alone and in combination with E. globulus and J. regia was also tested. A synergistic effect was considered when the bioactivity of the antimicrobials in combination was higher than the sum of the effect of each agent alone [23]. All experiments were performed in triplicate and repeated on three different occasions. 


\subsection{Statistical Analysis}

Data were analyzed using one-way analysis of variance (ANOVA) and means were compared using Tukey's honestly significant difference (HSD) multiple comparisons test. All statistical tests were performed using the Prism software package (GraphPad Software version 6.0 for Macintosh). Results were considered statistically significant when $p<0.05$.

\section{Conclusions}

In overall, this study highlighted the problem of emerging resistant species to antimicrobial agents. In fact, penicillin $G$, one of the main therapeutic strategies used in the prevention and treatment of $\mathrm{BM}$, seemed to be ineffective against planktonic cells of the most resistant strains $(50 \%$ of the tested isolates). On the other hand, non-cytotoxic concentrations of E. globulus exerted a bacteriostatic effect. Moreover, depending on the level of resistance evidenced by S. aureus strains to penicillin G, penicillin alone and in combination with E. globulus and/or J. regia seems to be promissory strategies to control bovine mastitis infections. In this sense, this study drew attention to a worrying problem concerning $\mathrm{BM}$ and evidenced the clear and urgent need to discover effective therapeutic strategies to control and to manage this pathology.

Author Contributions: F.G. and M.E.R. contributed to the study conception, design and data collection analysis. F.G., N.M. and M.H. contributed to the results interpretation. N.M., I.C.F.R.F. and M.H. critically reviewed the manuscript. All authors have read and approved the final manuscript.

Funding: The APC was funded by N. Martins.

Acknowledgments: This study was supported by the Portuguese Foundation for Science and Technology (FCT) (grants number SFRH/BPD/84488/2012 and SFRH/BPD/95401/2013) under the scope of the strategic funding of UID/BIO/04469/2013 unit and COMPETE 2020 (POCI-01-0145-FEDER-006684) and BioTecNorte operation (NORTE-01-0145-FEDER-000004) funded by European Regional Development Fund under the scope of the Norte2020 Programa Operacional Regional do Norte, as also Pest-OE/AGR/UI0690/2014 to CIMO. The authors also acknowledge Ana Maria Carvalho for the collection and identification of the wild samples, chemically characterized in previous studies. N. Martins would like to thank the Portuguese Foundation for Science and Technology (FCT-Portugal) for the Strategic project ref. UID/BIM/04293/2013 and "NORTE2020-Programa Operacional Regional do Norte" (NORTE-01-0145-FEDER-000012).

Conflicts of Interest: The authors declare no conflict of interest.

\section{References}

1. Rossi, C.C.; Aguilar, A.P.; Diaz, M.A.N.; Ribon, A.O.B. Aquatic plants as potential sources of antimicrobial compounds active against bovine mastitis pathogens. AFRICAN J. Biotechnol. 2011, 10, 8023-8030. [CrossRef]

2. Gomes, F.; Henriques, M. Control of Bovine Mastitis: Old and Recent Therapeutic Approaches. Curr. Microbiol. 2016, 72, 377-382. [CrossRef] [PubMed]

3. Kümmel, J.; Stessl, B.; Gonano, M.; Walcher, G.; Bereuter, O.; Fricker, M.; Grunert, T.; Wagner, M.; Ehling-Schulz, M. Staphylococcus aureus entrance into the Dairy Chain: Tracking S. aureus from dairy cow to cheese. Front. Microbiol. 2016, 7, 1603. [CrossRef] [PubMed]

4. Fagundes, H.; Barchesi, L.; Filho, A.N.; Ferreira, L.M.; Oliveira, C.A.F. Occurrence of Staphylococcus aureus in raw milk produced in dairy farms in são paulo state, Brazil. Braz. J. Microbiol. 2010, 41, 376-380. [CrossRef] [PubMed]

5. Sabour, P.M.; Gill, J.J.; Lepp, D.; Pacan, J.C.; Ahmed, R.; Dingwell, R.; Leslie, K. Molecular typing and distribution of Staphylococcus aureus isolates in eastern canadian dairy herds. J. Clin. Microbiol. 2004, 42, 3449-3455. [CrossRef] [PubMed]

6. Mordmuang, A.; Shankar, S.; Chethanond, U.; Voravuthikunchai, S.P. Effects of Rhodomyrtus tomentosa leaf extract on staphylococcal adhesion and invasion in bovine udder epidermal tissue model. Nutrients 2015, 7, 8503-8517. [CrossRef] [PubMed]

7. Bajaj, Y. Biotechnology in Agriculture and Forestry, 8th ed.; Springer Edition: New York, NY, USA; Berlin, Germany, 1995. 
8. $\quad$ Sugimoto, K.; Nakagawa, K.; Hayashi, S.; Amakura, Y.; Yoshimura, M.; Yoshida, T.; Yamaji, R.; Nakano, Y.; Inui, H. Hydrolyzable Tannins as Antioxidants in the Leaf Extract of Eucalyptus globulus Possessing Tyrosinase and Hyaluronidase Inhibitory Activities. Food Sci. Technol. Res. 2009, 15, 331-336. [CrossRef]

9. Boulekbache-Makhlouf, L.; Meudec, E.; Mazauric, J.-P.; Madani, K.; Cheynier, V. Qualitative and semi-quantitative analysis of phenolics in Eucalyptus globulus leaves by high-performance liquid chromatography coupled with diode array detection and electrospray ionisation mass spectrometry. Phytochem. Anal. 2013, 24, 162-170. [CrossRef] [PubMed]

10. Elliot, W.; Jones, D. The Encyclopaedia of Australian Plants; Lothian Publishing Company: Melbourne, Australia, 1986.

11. Panth, N.; Paudel, K.R.; Karki, R. Phytochemical profile and biological activity of Juglans regia. J. Integr. Med. 2016, 14, 359-373. [CrossRef]

12. Santos, A.; Barros, L.; Calhelha, R.C.; Dueñas, M.; Carvalho, A.M.; Santos-Buelga, C.; Ferreira, I.C.F.R. Leaves and decoction of Juglans regia L.: Different performances regarding bioactive compounds and in vitro antioxidant and antitumor effects. Ind. Crops Prod. 2013, 51, 430-436. [CrossRef]

13. Adnan, M.; Alshammari, E.; Ashraf, S.A.; Patel, K.; Lad, K.; Patel, M. Physiological and Molecular Characterization of Biosurfactant Producing Endophytic Fungi Xylaria regalis from the Cones of Thuja plicata as a Potent Plant Growth Promoter with Its Potential Application. BioMed Res. Int. 2018, 2018, 7362148. [CrossRef] [PubMed]

14. Martins, N.; Ferreira, I.C.F.R.; Barros, L.; Carvalho, A.M.; Henriques, M.; Silva, S. Plants used in folk medicine: The potential of their hydromethanolic extracts against Candida species. Ind. Crops Prod. 2015, 66, 62-67. [CrossRef]

15. Gomes, F.; Martins, N.; Barros, L.; Oliveira, M.B.; Rodrigues, M.E.; Henriques, M.; Ferreira, I. Plant phenolic extracts as an effective strategy to control Staphylococcus aureus, the dairy industry pathogen. Ind. Crops Prod. 2018, 112, 515-520. [CrossRef]

16. Wang, D.; Wang, Z.; Yan, Z.; Wu, J.; Ali, T.; Li, J.; Lv, Y.; Han, B. Bovine mastitis Staphylococcus aureus: Antibiotic susceptibility profile, resistance genes and molecular typing of methicillin-resistant and methicillin-sensitive strains in China. Infect. Genet. Evol. 2015, 31, 9-16. [CrossRef] [PubMed]

17. Temocin, F.; Erdinc, F.S.; Tulek, N.; Demirelli, M.; Ertem, G.; Kinikli, S.; Koksal, E. Synergistic effects of sulbactam in multi-drug-resistant Acinetobacter baumannii. Braz. J. Microbiol. 2015, 46, 1119-1124. [CrossRef]

18. Pinho, E.; Ferreira, I.C.F.R.; Barros, L.; Carvalho, A.M.; Soares, G.; Henriques, M. Antibacterial Potential of Northeastern Portugal Wild Plant Extracts and Respective Phenolic Compounds. BioMed Res. Int. 2014, 2014, 814590. [CrossRef]

19. Aldulaimi, O.A. General Overview of Phenolics from Plant to Laboratory, Good Antibacterials or Not. Pharmacogn. Rev. 2017, 11, 123-127. [CrossRef]

20. Amin, M.U.; Khurram, M.; Khan, T.A.; Faidah, H.S.; Shah, Z.U.; Ur Rahman, S.; Haseeb, A.; Ilyas, M.; Ullah, N.; Khayam, S.M.U.; et al. Effects of luteolin and quercetin in combination with some conventional antibiotics against methicillin-resistant Staphylococcus aureus. Int. J. Mol. Sci. 2016, 17, 1947. [CrossRef]

21. Martins, N.; Barros, L.; Ferreira, I.C.F.R. In vivo antioxidant activity of phenolic compounds: Facts and gaps. Trends Food Sci. Technol. 2016, 48, 1-12. [CrossRef]

22. Ferreira, C.; Pereyra, A.; Patriarca, A.; Mazzobre, M.; Polak, T.; Abram, V.; Buera, M.; Poklar Ulrih, N. Phenolic compounds in extracts from Eucalyptus globulus leaves and Calendula officinalis flowers. J. Nat. Prod. Resour. 2016, 2, 53-59.

23. Bollenbach, T. Antimicrobial interactions: Mechanisms and implications for drug discovery and resistance evolution. Curr. Opin. Microbiol. 2015, 27, 1-9. [CrossRef] [PubMed]

(C) 2019 by the authors. Licensee MDPI, Basel, Switzerland. This article is an open access article distributed under the terms and conditions of the Creative Commons Attribution (CC BY) license (http://creativecommons.org/licenses/by/4.0/). 